\title{
Rapid development of motor seizures in rats barpressing for electrical stimulation of the preoptic area
}

\author{
N. W. MILGRAM, H. LAWRENCE SMITH, and SUE MAY CHONG \\ Scarborough College, University of Toronto, West Hill, Ontario MIC 1A4, Canada
}

\begin{abstract}
Animals barpressing for rewarding electrical stimulation of the lateral preoptic area typically had well-developed motor seizures during their first self-stimulation session. Over subsequent daily testing, however, the incidence of self-induced seizures decreased significantly. In a second experiment, externally controlled delivery of stimulation was not found to induce a high proportion of first-session seizures but, over repeated daily sessions, there was a significant increase in elicited seizures. The rapid development of the first-session seizures is attributed to the highly potentiating consequences of the pattern of self-stimulation. The decrease in seizures over repeated daily self-stimulation testing is suggested to reflect learned avoidance of self-induced seizures.
\end{abstract}

Although it is well known that motor seizures can be triggered by electrical stimulation at various limbic system loci, seizures are rarely elicited when brain stimulation is first applied. The triggering of motor seizures generally depends on the animals having previously received a program of brain stimulation. Motor seizures can be "kindled" by repeatedly administering brief trains of stimulation, providing that the interval between each train is relatively long (generally hours or days); seizures develop less efficiently or not at all during the continuous application of brain stimulation or with short interstimulation intervals (Goddard, McIntyre, \& Leech, 1969; Racine, Burnham, Gartner, \& Levitan, 1973). Although the kindling of motor seizures by repeated stimulation at long intervals has been well substantiated, the absence of first-trial seizures appears dependent on the selection of the relatively high-frequency stimulation patterns typically used in brain stimulation studies (generally single trains at a frequency of $50-100 \mathrm{~Hz}$ ). Racine, Burnham, and Gartner (1973) found that first-trial motor seizures could be elicited within a 10-min interval either if brief trains of high-frequency stimulation $(300 \mathrm{~Hz})$ were delivered at a low train frequency $(2$ or $3 / \mathrm{sec})$ or if continuous stimulation was delivered within the relatively low-frequency range which supports recruiting. This rapid development of motor seizures appears to reflect the selection of stimulation patterns which produce potentiationlike effects.

This research was supported by National Research Council Grant 7659 to N. W. Milgram. Reprint requests should be sent to N. W. Milgram, Scarborough College, University of Toronto, West Hill, Ontario M1C, 1A4, Canada.
The present report describes an instance of a rapid development of seizures in response to $60-\mathrm{Hz}$ sinewave stimulation of the preoptic area. The observations were made during a preliminary phase of an experiment which required that animals be trained to barpress for electrical stimulation of the preoptic area. The large majority of animals tested learned to barpress and exhibited well-developed motor seizures during this first training session. Surprisingly, there was a decrease in intrasession motor seizures over subsequent testing. In a second experiment, employing externally controlled brain stimulation, the incidence of first-session motor seizures was substantially lower than when the animals were able to control the delivery of stimulation. In addition, there was a marked increment in intrasession seizures when the stimulation was externally controlled.

\section{EXPERIMENT 1}

\section{Method}

The subjects used in this experiment were 18 naive male hooded rats which weighed $320-350 \mathrm{~g}$ at the time that referential electrodes, made from sharpened $80 \%$ platinum $20 \%$ irridium wire, $228.6 \mu$ in diameter, were stereotaxically implanted into the lateral preoptic area. The electrode tips were aimed at a point $8.0 \mathrm{~mm}$ below the surface of the skull and $2.0 \mathrm{~mm}$ lateral to bregma with the surface of the skull parallel to the base of the stereotaxic instrument.

Following a postsurgical recovery interval of at least 1 week, the animals were placed in transparent Plexiglas testing boxes enclosed in lighted white chambers with a one-way mirror to allow uninterrupted observation. The testing boxes were equipped with levers which, when depressed, delivered a $.5-\sec 60-\mathrm{Hz}$ sine-wave stimulus between the referential stimulating electrode and an indifferent electrode that was attached to jeweler's screws implanted in the skull.

A shaping procedure was used to train the animals to barpress for preoptic stimulation. This first involved the adjustment of the 
current intensity to a level which produced vigorous approach behavior $(30-80 \mu \mathrm{A}, \mathrm{rms})$. Subsequently, the animals were shaped to barpress by delivery of the stimulation as the animal approached the lever. After acquiring the barpressing response, each animal remained in the testing box until it had pressed the lever 1,000 times, at which point the session was terminated and the animal was returned to its home cage. The animals were retested for selfstimulation at 24-h intervals on five additional sessions, each of which terminated after 1,000 leverpresses.

Throughout the six testing sessions, each elicited motor seizure was categorized using the following 5-level scale, modified from that described by Racine (1972): (1) rhythmic mouth movements; (2) rhythmic mouth movements accompanied by head nodding; (3) the above with bilateral tonic-clonic forelimb movements; (4) the above with the addition of rearing; (5) the above with tonic-clonic hindlimb movements and loss of postural control. In order to distinguish true motor seizures from stimulation-bound motor activity, the criteria were applied only if the observed behavior persisted following the offset of stimulation. The stimulator was disconnected from the bar immediately following the onset of any seizures rated at Level 3 or higher. The bar was again connected to the stimulator following the cessation of convulsive activity.

\section{Results}

Sixteen animals learned to barpress for stimulation of the preoptic area during their first training session. The two animals that did not learn during this short period of time were eliminated from the experiment. As illustrated in Table 1, a large proportion of the animals had one or more motor seizures during the first testing session. In 10 instances, these first session seizures were categorized as Level 3 or higher, and these well developed responses were typically the first indices of elicited seizures. Thus, a progressive development of seizures was not observed. Since this experiment was not initially designed to study seizure development, the number of stimulations preceding the first seizure was not recorded in all animals during the first session. However, estimates of stimulations, including the stimuli received during shaping, ranged from 150 to 500 .

Table 1 also shows that there was a notable decrease in the incidence of convulsions over repeated daily testing. This decrease was manifested by a tendency for fewer animals to exhibit any evidence of seizures; a decrease in the number of seizures per session for those animals which did seize; and finally a progressive daily increment in the number of stimulations required to trigger seizures. A comparison of cumulative seizures revealed this trend to be significant across daily sessions $\left(\chi^{2}=17.665, \mathrm{df}=5, \mathrm{p}<.01\right)$.

Histological examination following the conclusion of testing indicated that the electrode tips were all located within the region of the lateral preoptic area illustrated in Figure 1.

\section{Discussion}

The rapid development of motor seizures in animals barpressing for electrical stimulation to the preoptic area was unexpected. In the present experiment, the average interval between each brief stimulation was typically around $1 \mathrm{sec}$, which is considerably shorter than that previously found to be effective in producing seizure development (Goddard et al., 1969). Possibly the first session seizure development was a consequence of this very rapid presentation of short stimulation trains. This suggestion is consistent with evidence of intrasession seizure development when relatively short stimulation trains are delivered at fast repetition rates to the amygdala (Racine et al., 1973) and hippocampus (Taber, McNamara, \& Zornetzer, 1976). It is not clear, however, to what extent the use of a self-stimulation procedure contributed to the present results.

The results of this experiment also revealed a decrement in seizures over repeated daily selfstimulation testing, which was also unexpected, since it is well established that seizure susceptibility actually increases following repeated stimulation. The failure to observe an increase in seizures over repeated selfstimulation testing might be attributable to a temporary elevation in seizure threshold due to the relatively massive stimulation received during each daily session. There is evidence of an increase in seizure thresholds following seizures (Herberg, Tress, \& Blundell, 1969; McIntyre \& Goddard, 1973). However, the duration of this effect seems to be less than $24 \mathrm{~h}$ when the locus of stimulation is held constant, as was true in the present experiment. Possibly, the

Table 1

Motor Seizures Over the Course of Six Daily Self-Stimulation Sessions

\begin{tabular}{|c|c|c|c|c|c|}
\hline & \multirow{2}{*}{$\begin{array}{l}\text { Percent of Animals } \\
\text { Seizing During } \\
\text { Session }(N=16)\end{array}$} & \multicolumn{2}{|c|}{$\begin{array}{c}\text { Number of Seizures } \\
\text { per Animal* }\end{array}$} & \multicolumn{2}{|c|}{$\begin{array}{l}\text { Number of Stimulations } \\
\text { Preceding First Seizure* }\end{array}$} \\
\hline & & Mean & Range & Mean & Range \\
\hline Session 1 & 81.25 & 1.80 & $1-4$ & N.A. & N.A. \\
\hline Session 2 & 37.50 & 2.50 & $1-4$ & 143 & $63-285$ \\
\hline Session 3 & 50.00 & 1.30 & $1-2$ & 218 & $9-624$ \\
\hline Session 4 & 43.70 & 1.50 & $1-3$ & 348 & $154-569$ \\
\hline Session 5 & 43.70 & 1.10 & $1-2$ & 238 & $27-550$ \\
\hline Session 6 & 25.00 & 1.00 & 1 & 676 & $601-805$ \\
\hline
\end{tabular}

*Based only on animals having one or more seizures. 

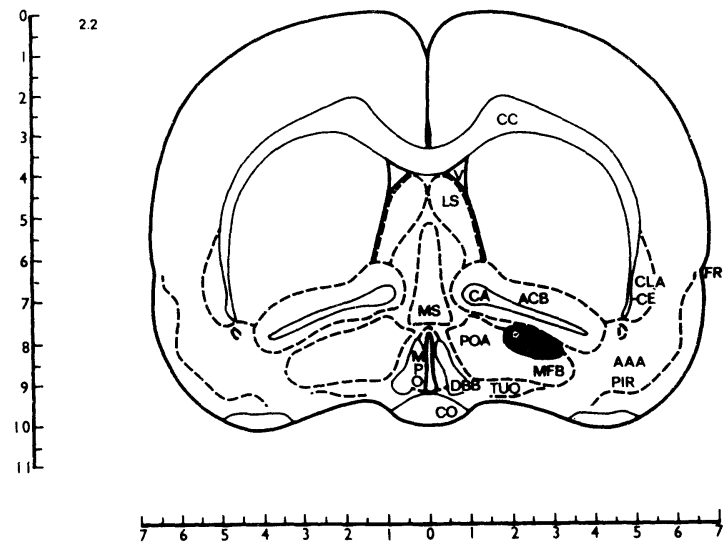

Figure 1. Electrode tips, as verified by histological examination, were located within the cross-hatched area. The number in the upper left-hand corner of the diagram indicates A-P coordinates with reference to bregma. Atlas diagrams are from Pellegrino and Cushman (1967).

duration of the elevation in seizure threshold is lengthened by the type of massive stimulation administered in the present experiment. It is also possible that the decrement in seizures over repeated testing may relate to some aspect of the use of the selfstimulation procedure.

\section{EXPERIMENT 2}

To examine the extent to which the findings reported in the first experiment were contingent upon the use of a self-stimulation procedure, a second experiment was performed, in which trains of 1,000 daily sine-wave stimulations were delivered automatically. The current intensity selected was the mean of the values used in the first experiment, and the train frequency approximated the mean of the selfstimulation rates.

\section{Methods}

Seven male hooded rats were implanted with stimulating electrodes aimed at the same preoptic loci studied in Experiment 1. Six days following surgery, each animal was placed in test cham- bers which were identical to those used in the first experiment, except that the bar was disconnected from the stimulator. The animals then received $.5-\mathrm{sec}$ trains of $60-\mathrm{Hz}$ sine-wave stimulation at a repetition frequency of $1.2 \mathrm{sec}$ and a current intensity of $54 \mu \mathrm{A}(\mathrm{rms})$. A session was terminated after the animals had received a total of $1,000.5-\mathrm{sec}$ trains. The same procedure was then repeated for 5 additional days. Seizures were categorized as described in Experiment 1. The stimulator was turned off for a 5-min interval following the onset of each seizure.

\section{Results}

In this experiment, only one of the seven experimental animals was observed to have a motor seizure during the initial session. The seizure observed in this animal was categorized as Level 2 . Over subsequent testing, however, there was an incremental increase in the number of animals having seizures and in the incidence of multiple convulsions per animal (Table 2). A comparison of cumulative seizures per session revealed a highly significant trend across daily session $\left(\chi^{2}=23.16, \mathrm{df}=5, \mathrm{p}<.001\right)$. In addition, there was a decreasing trend in the mean number of stimulations required to elicit seizures.

Histological examination following the conclusions of testing indicated that the electrode tips were located within the same region of the lateral preoptic area described in the previous experiment.

\section{Discussion}

The first experiment demonstrated that rats were likely to experience motor seizures shortly after learning to barpress for rewarding stimulation to the preoptic area. This unexpectedly rapid development of motor seizures is attributable in part to the pattern in which the animals delivered electrical stimulation to the brain. In the second experiment, there was a low incidence of first-session motor seizures when the delivery of stimulation to the lateral preoptic area was externally controlled and the parameters (rate and intensity) were otherwise equated with those of experiment one. The first-session seizure development probably also reflects characteristics peculiar to the lateral preoptic area: we know of no other findings of first-session seizures during self-stimulation, and

Table 2

Motor Seizures Over the Course of Six Daily Sessions Employing Externally Controlled Stimulation

\begin{tabular}{|c|c|c|c|c|c|}
\hline & \multirow{2}{*}{$\begin{array}{l}\text { Percent of Animals } \\
\text { Having One or More } \\
\text { Seizures }(\mathrm{N}=7)\end{array}$} & \multicolumn{2}{|c|}{$\begin{array}{c}\text { Number of Seizures } \\
\text { per Animal* }\end{array}$} & \multicolumn{2}{|c|}{$\begin{array}{l}\text { Number of Stimulations } \\
\text { Preceding First Seizure* }\end{array}$} \\
\hline & & Mean & Range & Mean & Range \\
\hline Session 1 & 14.29 & 1.00 & 1 & 946 & 946 \\
\hline Session 2 & 57.14 & 1.75 & $1-3$ & 609 & $117-997$ \\
\hline Session 3 & 71.40 & 2.00 & $1-5$ & 295 & $125-661$ \\
\hline Session 4 & 85.70 & 2.50 & $1-5$ & 309 & $34-604$ \\
\hline Session 5 & 85.70 & 3.16 & $1-6$ & 296 & $30-916$ \\
\hline Session 6 & 100.00 & 3.17 & $1-7$ & 41 & $20-170$ \\
\hline
\end{tabular}

*Based only on animals having one or more seizures. 
we have not observed rapid seizure development in animals trained to barpress for stimulation to the lateral hypothalamic area.

Although the occurrence of motor seizures during electrical self-stimulation of the brain is generally regarded as a nuisance, intrasession seizure development also reflects neurophysiological consequences of rewarding brain stimulation. In the present experiments, seizures were always preceded by a series of stimulation trains; the first stimulation of a session was never sufficient. Thus, the repeated delivery of brain stimulation must have some cumulative effect which is manifested by the eventual triggering of a motor seizure. A likely neurophysiological analogue for such a cumulative effect is the type of postactivation potentiation phenomenon observed during recruitment or posttetanic potentiation. Such a hypothesis is consistent with evidence by Racine et al. (1973) that the speed of intrasession seizure development in the amygdala is directly related to the extent of postactivation potentiation of the stimulation pattern used. From this perspective, the high incidence of first-session seizures during preoptic self-stimulation indicates a marked potentiating effect of the pattern of stimulation. Moreover, potentiation seems to develop more rapidly in animals self-stimulating than in animals administered stimulation at regular intervals.

Experiment 1 also showed that the incidence of electrically elicited seizures decreased over repeated daily self-stimulation sessions. Since the animals tested in the second experiment showed a significant increase in seizures over repeated daily testing, the results of the first experiment cannot be attributable to a long-lasting elevation in seizure threshold produced by massive brain stimulation. It is more likely that the rats were able to learn to modify their barpressing pattern so as to decrease the occurrence of seizures. This suggestion is supported by the finding of Herberg and Blundell (1969) that rats can learn to control the duration of rewarding stimulation in order to avoid eliciting motor seizures. In addition, there is evidence that barpressing rate increases following treatments which suppress the elicitation of seizures (Herberg \& Blundell, 1969; Newman, 1967; Olds, 1966; Reid, Gibson, Gledhill \& Porter, 1964).

\section{REFERENCES}

Goddard, G. V., McIntyre, D. C., \& LeEch, C. K. A permanent change in brain function resulting from daily electrical stimulation. Experimental Neurology, 1969, 25, 295-330.

Herberg, L. T., \& Blundell, J. E. Epileptiform seizures and the rat's choice of stimulus duration in electrical selfstimulation. Journal of Comparative and Physiological Psychology, 1969, 69, 442-447.

Herberg, L. T., Tress, K. H., \& Blundell, J. E. Raising the threshold in experimental epilepsy by hypothalamic and septal stimulation and by audiogenic seizures. Brain, 1969, 92, 313-328.

MCINTYRE, D. C., \& GoddaRd, G. V. Transfer, interface and spontaneous recovery of convulsions kindled from the rat amygdala. Electroencephalography and Clinical Neurophysiology, 1973, 35, 533-543.

NEWMAN, B. L. EEG correlates of self-stimulation. Journal of Comparative and Physiological Psychology, 1967, 63, 516-520.

OLds, M. E. Facilitatory action of diazepam and chlordiazepoxide on hypothalamic reward behavior. Journal of Comparative and Physiological Psychology, 1966, 62, 136-140.

Pellegrino, L. T., \& Cushman, A. J. Stereotaxic atlas of the rat brain. New York: Meredith, 1967.

RACINE, R. J. Modification of seizure activity by electrical stimulation: II. Motor-seizure. Electroencephalography and Clinical Neurophysiology, 1972, 32, 281-294.

Racine, R. J., Burnham, W. M., \& Gartner, J. G. First trial motor seizures triggered by amygdaloid stimulation in the rat. Electroencephalography and Clinical Neurophysiology, 1973, 35, 487-494.

Racine, R. J., Burnham, W. M., Gartner, J. G., \& Levitan, D. Rates of motor seizure development in rats subjected to electrical brain stimulation: Strain and interstimulation interval effects. Electroencephalography and Clinical Neurophysiology, 1973, 35, 553-556.

Reid, L. D., Gibson, W. E., Gledhill, S. M., \& Porter, P. B. Anticonvulsant drugs and self-stimulating behavior. Journal of Comparative and Physiological Psychology, 1964, 57, 353-356.

Taber, K. H., McNamara, J. J., \& Zornetzer, S. F. Status epilecticus: A new rodent model. Neuroscience Abstracts, 1976, 11, 268.

(Received for publication September 14, 1977; revision accepted November 21, 1977.) 